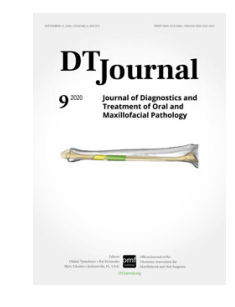

\title{
| The Covid-19 Pandemic and the DTJournal.org
}

\author{
Evangelos G. Kilipiris
}

\begin{abstract}
W e run the marathon of the Covid-19 pandemic, a novel and severe coronavirus (SARS-CoV-2) infection, an unprecedented crisis in modern medical times. This crisis has profoundly stressed health care systems worldwide by testing the limits of their capabilities, and abruptly changed the way of delivering care to our patients. Every aspect of the medical field has been heavily affected, and Oral-Maxillofacial Surgery services are no exception during these difficult circumstances. ${ }^{1}$ In addition, it posed a strict limit in the freedom of travel, and highly altered the global product supply chain, including personal protective equipment for the hospitals and health care workers. It gave rise to an economic crisis, very different from the previous experienced, with the economies trying to follow, modify and adapt their plans according to the virus spread, transmission and severity of regional clinical picture. Our social lives are altered with the introduction of distancing measures, and the wearing of face masks. All scientific meetings, globally and nationally, are cancelled, postponed or transformed to virtual events. ${ }^{2}$ The rapid adoption of digital technology revolutionized the delivery of healthcare and education. ${ }^{3}$

A new path has been formed, by crafting the workflow, based on this new normal. Because of the healthcare crisis of this magnitude, the aim of the Journal of Diagnostics and Treatment of Oral and Maxillofacial
\end{abstract}

Director, Journal Development Department, dtjournal.org; Thessaloniki, Greece | Bratislava, Slovak Republic.

E-mail: varonos@live.co.uk (Evangelos Kilipiris)

Instagram: @evangeloskilipiris

Please cite this article as: Kilipiris EG. The covid-19 pandemic and the dtjournal.org. J Diagn Treat Oral Maxillofac Pathol 2020;4(9):179-80.
Pathology (the website is dtjournal.org) is to publish important and accurate articles on the Covid-19 pandemic. This collection has been inaugurated by an article addressing the impact of the pandemic to the clinical and educational activities of our specialty. As the Covid-19 crisis is an evolving and dynamic event, and new health protocols are implemented and maturated, the collection of papers on Covid-19 at our journal will steadily expand with the addition of new content. For example, we anticipate articles, among others, on topics that highlight the global impact of Covid-19 on Oral and Maxillofacial Surgery, provide a picture of the challenges our specialty is facing, address preventive strategies, investigate the expanding role of telemedicine, creatively adjust new protocols, guidelines and workforce through the lens of Oral and Maxillofacial Surgery specialty, and share practical frameworks with the ultimate goal to continue the delivery of high quality care, in a new way, to the Oral and Maxillofacial Surgery population, but also to serve the broad medical community.

This disruptive challenge placed medical care in a new path within an uncharted territory. However, by running this long way with global collaboration, solidarity and adaptability, brilliant examples of innovation can emerge, the organization and preparedness of healthcare systems can improve, and the medical education with biomedical research will

Paper received 11 September 2020

Accepted 13 September 2020

Available online 30 September 2020

https://dx.doi.org/10.23999/j.dtomp.2020.9.5

(C) 2020 OMF Publishing, LLC. This is an open access article under the CC BY license (http://creativecommons.org/licenses/by-nc/4.0/). 
progress.

In this Covid-19 crisis, and on its rapidly evolving landscape, the Journal of Diagnostics and Treatment of Oral and Maxillofacial Pathology actively contributes by bringing free expanding literature, and extends to everyone in our international network the best wishes for health and safety.

\section{REFERENCES}

1. Patel NA, Ji YD, Odera SL. The role of oral and maxillofacial surgeons in COVID-19 response. J Oral
Maxillofac Surg 2020;78(7):1052-3. https://dx.doi. org/10.1016/j.joms.2020.04.016.

2. Maffia F, Fesenko II, Vellone V. Covid-2019 pandemic: growing wave of cancelled meetings in oral and maxillofacial surgery and its impact on specialty. $J$ Diagn Treat Oral Maxillofac Pathol 2020;4(8):125-8. https://dx.doi.org/10.23999/j.dtomp.2020.8.1.

3. Tymofieiev OO, Ushko NO, Yarifa MO. Covid-2019 response: virtual educational process at the department of oral and maxillofacial surgery using Google Classroom. J Diagn Treat Oral Maxillofac Pathol 2020;4(3):51-2. https://dx.doi.org/10.23999/j. dtomp.2020.3.1. 